\title{
Review Article \\ Progress in Studies on Carbon and Silicon Carbide Nanocomposite Materials
}

\author{
Peng Xiao, Jie Chen, and Xian-feng Xu \\ State Key Laboratory of Powder Metallurgy, Central South University, Changsha 410083, China \\ Correspondence should be addressed to Jie Chen, kittyjie1211@yahoo.com.cn
}

Received 28 June 2010; Accepted 11 October 2010

Academic Editor: Bohua Sun

Copyright () 2010 Peng Xiao et al. This is an open access article distributed under the Creative Commons Attribution License, which permits unrestricted use, distribution, and reproduction in any medium, provided the original work is properly cited.

Silicon carbide nanofiber and carbon nanotubes are introduced. The structure and application of nanotubers (nanofibers) in carbon/carbon composites are emphatically presented. Due to the unique structure of nanotubers (nanofibers), they can modify the microstructure of pyrocarbon and induce the deposition of pyrocarbon with high text in carbon/carbon composites. So the carbon/carbon composites modified by CNT/CNF have more excellent properties.

\section{Introduction}

Since the discovery of carbon nanotubes (CNT) by Japanese expert Iijima in 1991, the studies on CNT have been the frontier and hot in the field of new materials [1-3]. CNT has a large number of unique advantages, such as high aspect ratio, large surface area, excellent mechanical properties, and unique heat properties, so it is particularly suitable for the reinforcement of now composite materials $[4,5]$.

Silicon carbide whisker (SiCW) and Silicon carbide nanofiber (SiCNF) are a new type of ceramic fiber, which can prepared by the similar method as that of CNT. Compared with CNT, SiCW/SiCNF has more excellent mechanical, heat, electricity properties, and better physicalchemical stability [6-8]. Therefore SiCW/SiCNF has become the candidate materials for toughening phase of composite materials.

A carbon/carbon $(\mathrm{C} / \mathrm{C})$ composite is the carbon fiber reinforced carbon matrix composite. Due to their low density, excellent mechanical and thermal properties, $\mathrm{C} / \mathrm{C}$ composites have been widely used in aviation and space industries for rocket nozzles, missile nosetips, re-entry heatshields, nose and leading edges of space shuttle, brake discs for aeroplane, and so forth $[9,10]$. Carbon fibers are the reinforcement of carbon/carbon $(\mathrm{C} / \mathrm{C})$ composites; the volume fraction of carbon fibers is less than $40 \%$. The properties of $\mathrm{C} / \mathrm{C}$ composites largely depend on the performance of carbon fibers and the bonding state between carbon fibers and carbon matrix [11, 12]. Carbon fibers belong to brittle materials and have low surface activity, so fiber surface modification is necessary to improve the performance of $\mathrm{C} / \mathrm{C}$ composites. Due to the unique properties of nanotubes/nanofibers, fiber surface modification by $\mathrm{CNT} / \mathrm{SiCNF}$ is a good research direction.

\section{Structure and Preparation of CNT}

2.1. Structure of CNT. CNT is composed entirely of carbon atoms and it is a nanotube rolled up by singe or multilayer of graphene, as shown in Figure 1 [13]. According to the different crimp angle and diameter of graphenes, CNTs have different characteristics, including left rotation, right rotation and non rotation. The CNT rolled up by a single layer of graphene is single-walled carbon nanotubes and the CNT rolled up by several layers of graphene is multiwalled carbon nanotube. The diameter of CNT is about $1 \sim 50 \mathrm{~nm}$ and the length is up to few microns $[14,15]$. So CNT is considered as the a typical one-dimensional nanomaterial.

2.2. Preparation of CNT. The main preparation methods of CNT are arc discharge, catalysis decomposition, laser evaporation, and plasma method [16-18]. The mature technology are the discharge of graphite arc and catalysis decomposition of hydrocarbons. 


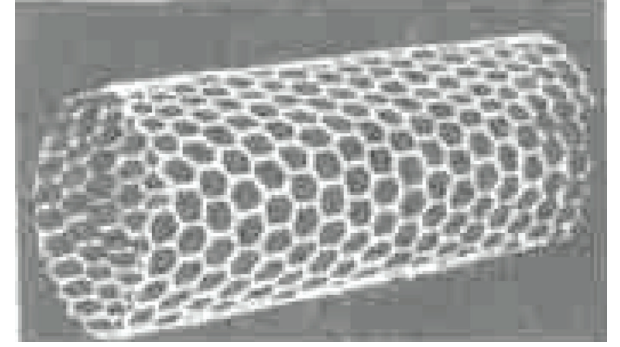

FIGURE 1: The structure of CNT.

The arc discharge method is the traditional method for CNT preparation. Under inert atmosphere at certain pressure, two graphite rods, a few millimeters apart, are used as anode and cathode, respectively. In strong current, arc discharge takes place between two graphite electrodes. The anode graphite is consumed continuously and the sediments including CNT, fullerene, graphite, and other forms of carbon deposit on the cathode graphite. Due to the simple test equipment, the arc discharge method is widely used by many researchers.

However, the CNT prepared by arc discharge method contains many impurities. Catalysis decomposition of hydrocarbons is a more promising method. This method is the decomposition of of hydrocarbons to generate free carbon atoms and then form the CNT, with $\mathrm{Fe}$, $\mathrm{Co}$, or $\mathrm{Ni}$ as catalyst. Due to the high purity, and the uniform size distribution of CNT produce by catalysis decomposition of hydrocarbons, this method has been widely used and has made great progress. On the other hand, continuous highvolume industrial productions of CNT with high quality and efficiency are studied positively. Xie si-sheng has created a new method which can obtain CNT array with uniform diameter $(20 \mathrm{~nm}), 100 \mathrm{~nm}$ tube spacing, high purity and high density [19]. Chen changxin has developed pulsed laser ablation to prepare CNT. Zhu hongwei has realized the low-cost mass production of single-walled CNT by vertical floating catalyst method [20].

\section{Structure and Preparation of SiCW/SiCNF}

3.1. Structure of SiCW/SiCNF. SiCW is a kind of single crystal materials of short fibers with high orientation. SiCW has the diameter of nanometer to millimeter and has no grain boundary, few chemical impurities and structure defects, and big aspect ratio. The strength of SiCW is close to the binding force between atoms, so it is the material which has the closest strength with the theory strength of crystal, with high specific strength and specific elastic modulus [7].

SiCNF is a new kind of ceramic fibers, which has superior properties and good compatibility with ceramic matrix, compared with carbon fibers. At the same time, SiCNF is an ideal kind of inorganic reinforcing fibers with constructure, stealth and heat-resistance in one [8].

3.2. Preparation of SiCW/SiCNF. SiCW is a kind of crystal of extreme anisotropy and it is a short fibrous crystal growing on $\langle 111\rangle$ surface of $\mathrm{SiC}$ particle by catalyst. The methods to prepare SiCW are gas reaction and solid reaction $[21,22]$. Gas reaction refers that carbonaceous gases react with silicon gases to synthesis $\mathrm{SiCW}$ and solid reaction refers that the mixture containing carbon and silicon synthesis $\mathrm{SiCW}$ by certain carrier gases. In the two methods, solid reaction is more economical and more suitable for industrial production. Solid method includes vapor-liquid-solid (VLS) mechanism and vapor-liquid (VL) mechanism. VLS is that liquid phase of carbon and silicon react by the catalysts of $\mathrm{Fe}$, $\mathrm{Ni}$, or $\mathrm{NaF}$ and then precipitate $\mathrm{SiCW}$ by supersaturation. $\mathrm{VL}$ is that vapor $\mathrm{SiO}$ and $\mathrm{CO}$ react get $\mathrm{SiC}$ which is the nucleation point to synthesis $\mathrm{SiCW}$.

The main preparation methods of SiCNF are chemical vapor deposition (CVD), sintering of ultrafine powder, transformation of active carbon fiber, and transformation of organic precursor [23]. CVD and transformation of organic precursor have realized industrialization, but the SiCNF prepared by the two methods has big diameter, poor flexibility, and high cost. So the chemical vapor growth (CVG) has received lots of attention gradually. Wallenberger and his companion have prepared SiCNF with diameter of $30 \sim 136$ um by laser CVD under atmospheric pressure of $120 \mathrm{kPa}$ [24]. Wang has prepared $\mathrm{SiC}$ nanowire with diameter of $20 \mathrm{~nm} \sim 15 \mathrm{um}$ and length larger than $10 \mathrm{um}$ by the in situ CVG. Xie zhengfa has got SiCNF with high aspect ratio by CVG [25].

\section{Nanofiber Reinforced C/C Composites}

4.1. Application of Nanofibers in C/C Composites. CNT/CNF are typical one-directional nanomaterials, which have good mechanical properties, excellent conductivity, big surface area, high strength, and modulus [26, 27]. Recent studies show that thermal conductivity of ceramics and pyrocarbon has been enhanced significantly after being reinforced by CNTs [28]. It has been reported by the author that CNT/CNF can improve the bonding between pyrocarbon and carbon fibers of $\mathrm{C} / \mathrm{C}$ composites, which induces the deposition of pyrocarbon with high texture during CVD, as shown in Figure 2. CNT/CNF and pyrocarbon are all constituted by carbon, so the interface between them has good wettability. In situ grown CNT/CNF on the surface of carbon fibers can effectively remedy the anisotropy of preforms waved by carbon fibers. Therefore, CNT/CNF is expected to really improve the mechanical and thermal properties of $\mathrm{C} / \mathrm{C}$ composites.

Due to the excellent properties of $\mathrm{SiCW} / \mathrm{SiCNF}$, they are widely used as the toughening phase in $\mathrm{C} / \mathrm{C}$ composites. There is residual stress at the interface between $\mathrm{SiCW} / \mathrm{SiCNF}$ and matrix for the different coefficients of thermal expansion between them. When the microcracks extent to the interface between SiCW/SiCNF and matrix due to the external forces, the tip stress of microcracks will be absorbed by the residual stress of interface, according to the investigation of the author's research team. So the existence of SiCW/SiCNF can prevent further expansion of microcracks and then toughen the composites by the method of bridge or crack deflection. In $\mathrm{C} / \mathrm{C}$ composites, evenly dispersed $\mathrm{SiCW} / \mathrm{SiCNF}$ have good 


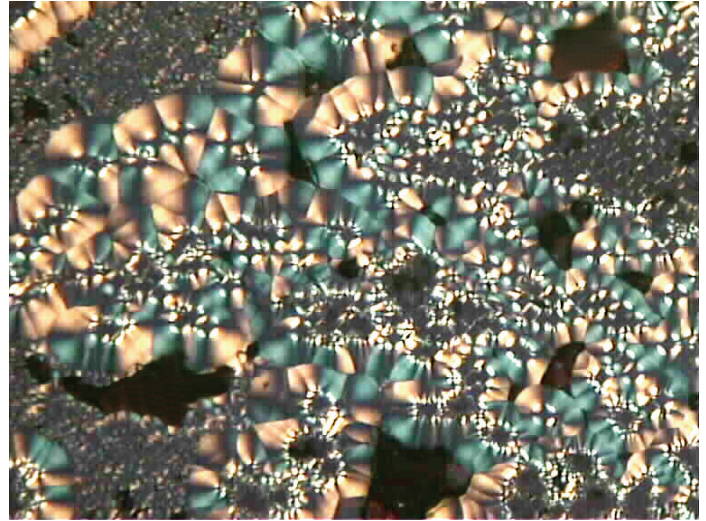

FIGURE 2: PLM images of composites modified by CNT.

match with carbon matrix. Due to the high temperature stability of SiCW/SiCNF, the composites reinforced by them can keep good mechanical properties up to $1273 \mathrm{~K}$.

4.2. Adding Methods of Nanofibers in C/C Composites. The main methods to add nanofibers to $\mathrm{C} / \mathrm{C}$ composites are as follows.

(1) Impregnation (see [26]). CNT/CNF are mixed with pitch or resin firstly. Then the carbon preform are impregnated in this pitch or resin, so CNT/CNF are added into $\mathrm{C} / \mathrm{C}$ composites. However, CNT/CNF have large surface area and big surface energy which made CNT/CNF easy to reunite and difficult to disperse uniformly.

(2) Directional Growth (see [29]). The directionally grown CNTs directly reinforce the pyrocarbon. This method is limited to prepare nanoscale materials.

(3) Situ Growth Method (see [30]). CNT/CNF are in situ grown on the surface of carbon fibers in carbon preforms and then this preforms are densified to get $\mathrm{C} / \mathrm{C}$ composites. In this method, CNT/CNF can grow uniformly on the surface of carbon fibers, so the uniform dispersion of CNT/CNF are solved and they work as a bridge between carbon fibers.

\section{The Effect of Nanofibers on the Microstructure and Property of C/C Composites}

The author and his group prepared CNT or SiCNF on the fiber surface of preforms by CCVD with electroplated $\mathrm{Ni}$ as catalyst. The CNT or SiCNF modified preforms were then densified by CVD. The effect of nanofibers on the microstructure and property of $\mathrm{C} / \mathrm{C}$ composites were systematically studied.

The in situ grown CNT or SiCNF have high degree of orientation, which increases the surface area and improves the surface activity of carbon fibers. The CNT or SiCNF on the fiber surface induces the interfacial layer of high texture during the deposition of pyrocarbon. Raman spectroscopy

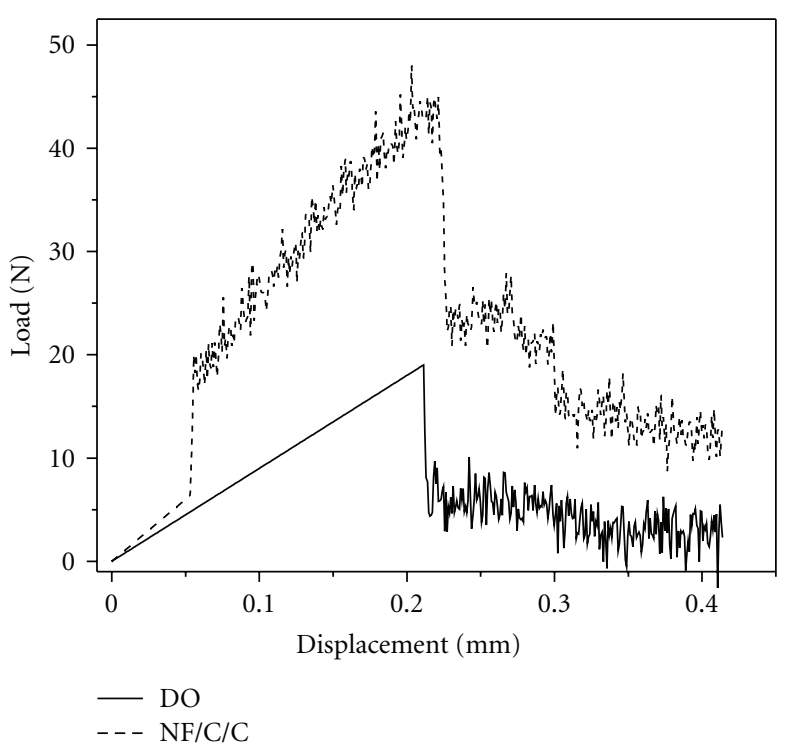

FIGURE 3: Displacement-load curve of the samples (// the axis of $\mathrm{CF})$.

shows that the graphitization degree of pyrocarbon near carbon fibers are significantly improved. Therefore the thermal conductivity of $\mathrm{C} / \mathrm{C}$ composites is significantly enhanced, especially in the direction perpendicular to fiber axis with the maximum increase of $80 \%$.

Due to the in situ grown CNT or SiCNF on the fiber surface, there is a good bridge between carbon fibers which improve the deposition mode of pyrocarbon and adjust the interfacial bonding between carbon fibers and pyrocarbon. On the other hand, the CNT or SiCNF on fiber surface have toughening effect which changes the fracture mode of $\mathrm{C} / \mathrm{C}$ composites. Therefore the mechanical properties of composites are significantly enhanced. In author's studies, three-point bending method is used to compare the bending strength between $\mathrm{C} / \mathrm{C}$ composites and modified $\mathrm{C} / \mathrm{C}$ composites. Figure 3 shows the displacement-load curve of samples. In the direction of fiber axis, the bending strength is enhanced by $182 \%$ and the compressive strength is enhanced by $71 \%$.

\section{Conclusions}

$\mathrm{CNT} / \mathrm{CNF}$ are typical one-directional nanomaterials and have particular microstructure. SiCNF and CNT are the good adding phase in $\mathrm{C} / \mathrm{C}$ composites which can modify the microstructure of pyrocarbon and induce the deposition of pyrocarbon with high text. So the $\mathrm{C} / \mathrm{C}$ composites modified by $\mathrm{CNT} / \mathrm{CNF}$ have more excellent properties.

\section{References}

[1] S. Iijima, "Helical microtubules of graphitic carbon," Nature, vol. 354, no. 6348, pp. 56-58, 1991.

[2] F. T. Fisher, R. D. Bradshaw, and L. C. Brinson, "Fiber waviness in nanotube-reinforced polymer composites-I: modulus 
predictions using effective nanotube properties," Composites Science and Technology, vol. 63, no. 11, pp. 1689-1703, 2003.

[3] L. I. Xiu-xiu, L. I. Xiao-Dong, and Y. Rong-Jie, "Progress in functionalized treatment of carbon nanotubes," Carbon Techniques, vol. 23, no. 1, pp. 23-27, 2004.

[4] A. K.-T. Lau and D. Hui, "The revolutionary creation of new advanced materials - carbon nanotube composites," Composites Part B:Engineering, vol. 33, no. 4, pp. 263-277, 2002.

[5] A. Gomathi, M. Ramya Harika, and C. N. R. Rao, "Urea route to coat inorganic nanowires, carbon fibers and nanotubes by boron nitride," Materials Science and Engineering A, vol. 476, no. 1-2, pp. 29-33, 2008.

[6] J. Donald, "Silicon carbide whiskers," American Ceramic Society Bulletin, vol. 72, no. 6, p. 116, 1993.

[7] G. L. Vaughan, S. A. Trently, and R. B. Wilson, "Pulmonary response, in vivo, to silicon carbide whiskers," Environmental Research, vol. 63, no. 2, pp. 191-201, 1993.

[8] A. I. Kharlamov, N. V. Kirillova, and S. N. Kaverina, "Hollow silicon carbide nanostructures," Theoretical and Experimental Chemistry, vol. 38, no. 4, pp. 237-241, 2002.

[9] S. L. Lu and B. Rand, "Large diameter carbon filaments from mesophase pitch for thermal management applications," New Carbon Materials, vol. 15, no. 1, pp. 1-5, 2000.

[10] J. Chen, X. Xiong, P. Xiao, and H. -B. Zhang, “The catalytic effect of boric acid on polyacrylonitrile-based carbon fibers and the thermal conductivity of carbon/carbon composites produced from them," Carbon, vol. 48, no. 8, pp. 2341-2346, 2010.

[11] J. J.. Chen, Y. Pan, W. H. Tang et al., "Tuning the morphologies of $\mathrm{SiC}$ nanowires via the change of the CoxSiy melts," NanoMicro Letters, vol. 2, no. 1, pp. 11-17, 2010.

[12] S. Bae, H. Kim, and Y. Lee, "Progress on nanotube," Nature Nanotechnology, vol. 20, pp. 132-1375, 2010.

[13] Y. Gogotsi, J. A. Libera, N. Kalashnikov, and M. Yoshimura, “Graphite polyhedral crystals," Science, vol. 290, no. 5490, pp. 317-320, 2000.

[14] Y. R. Cho, J. H. Lee, and Y. H. Song, "Phootlihtography-based carbon nanotubes patterningf or fiedle msision dsipalys," Materials Science and Engineering B, vol. 79, p. 128, 2001.

[15] Z. L. Wang, P. Poncharal, and W. A. de Heer, "Measuring physica land mechancial properties of nidivdiua lcarbon nanoutbes by ni stiu TEM," Journal of Physics and Chemistry of Solids, vol. 611, p. 25, 2000.

[16] T. W. Ebbesen and P. M. Ajayan, "Large-scale synthesis of carbon nanotubes," Nature, vol. 358, no. 6383, pp. 220-222, 1992.

[17] H. W. Zhu, C. L. Xu, D. H. Wu, B. Q. Wei, R. Vajtai, and P. M. Ajayan, "Direct synthesis of long single-walled carbon nanotube strands," Science, vol. 296, no. 5569, pp. 884-886, 2002.

[18] S. Matsumoto, L. Pan, H. Tokumoto, and Y. Nakayama, "Selective growth of single-walled carbon nanotubes by chemical vapor deposition," Physica B, vol. 323, no. 1-4, pp. 275-276, 2002.

[19] S. S. Xie, "Carbon nanotubes and other nanometer materials," China Basic Science, vol. 5, pp. 4-7, 2000.

[20] C. Chen, W. Chen, and Y. Zhang, "Synthesis of carbon nanotubes by pulsed laser ablation at normal pressure in metal nano-sol," Physica E, vol. 28, no. 2, pp. 121-127, 2005.

[21] J. V. Milewski and F. D. Gac, "Growth of SiC Whiskers in the system $\mathrm{SiO}_{2}-\mathrm{C}-\mathrm{H} 2$ nucleated by iron," Journal of Materials Science, vol. 20, no. 8, pp. 1160-1168, 1985.
[22] W.-S. Seo, K. Koumoto, and S. Arai, "Effects of boron, carbon, and iron content on the stacking fault formation during synthesis of $\beta$-SiC particles in the system $\mathrm{SiO}_{2}-\mathrm{C}-\mathrm{H}_{2}$," Journal of the American Ceramic Society, vol. 81, no. 5, pp. 1255-1261, 1998.

[23] D. Zhou and S. Seraphin, "Production of silicon carbide whiskers from carbon nanoclusters," Chemical Physics Letters, vol. 222, no. 3, pp. 233-238, 1994.

[24] F. T. Wallenberger, "Inorganic fibres and microfabricated parts by laser assisted chemical vapour deposition (LCVD): structures and properties," Ceramics International, vol. 23, no. 2, pp. 119-126, 1997.

[25] Z.-F. Xie, D.-L. Tao, J. Wang, and J.-Y. Xiao, "Synthesis and characterization of silicon carbide fibers by chemical vapor growth," Chemical Journal of Chinese Universities, vol. 27, no. 9, pp. 1604-1607, 2006.

[26] Q.-M. Gong, Z. Li, X.-D. Bai, D. Li, and J. Liang, "The effect of carbon nanotubes on the microstructure and morphology of pyrolytic carbon matrices of $\mathrm{C}-\mathrm{C}$ composites obtained by CVI," Composites Science and Technology, vol. 65, no. 7-8, pp. 1112-1119, 2005.

[27] Q.-M. Gong, Z. Li, Z. Zhang et al., “Tribological properties of carbon nanotube-doped carbon/carbon composites," Tribology International, vol. 39, no. 9, pp. 937-944, 2006.

[28] J. Chen, X. Xiong, and P. Xiao, "The effect of carbon nanotube growing on carbon fibers on the microstructure of the pyrolytic carbon and the thermal conductivity of carbon/carbon composites," Materials Chemistry and Physics, vol. 116, no. 1, pp. 57-61, 2009.

[29] Q.-M. Gong, Z. Li, X.-W. Zhou, J.-J. Wu, Y. Wang, and J. Liang, "Synthesis and characterization of in situ grown carbon nanofiber/nanotube reinforced carbon/carbon composites," Carbon, vol. 43, no. 11, pp. 2426-2429, 2005.

[30] H. Allouche and M. Monthioux, "Chemical vapor deposition of pyrolytic carbon on carbon nanotubes. Part 2. Texture and structure," Carbon, vol. 43, no. 6, pp. 1265-1278, 2005. 

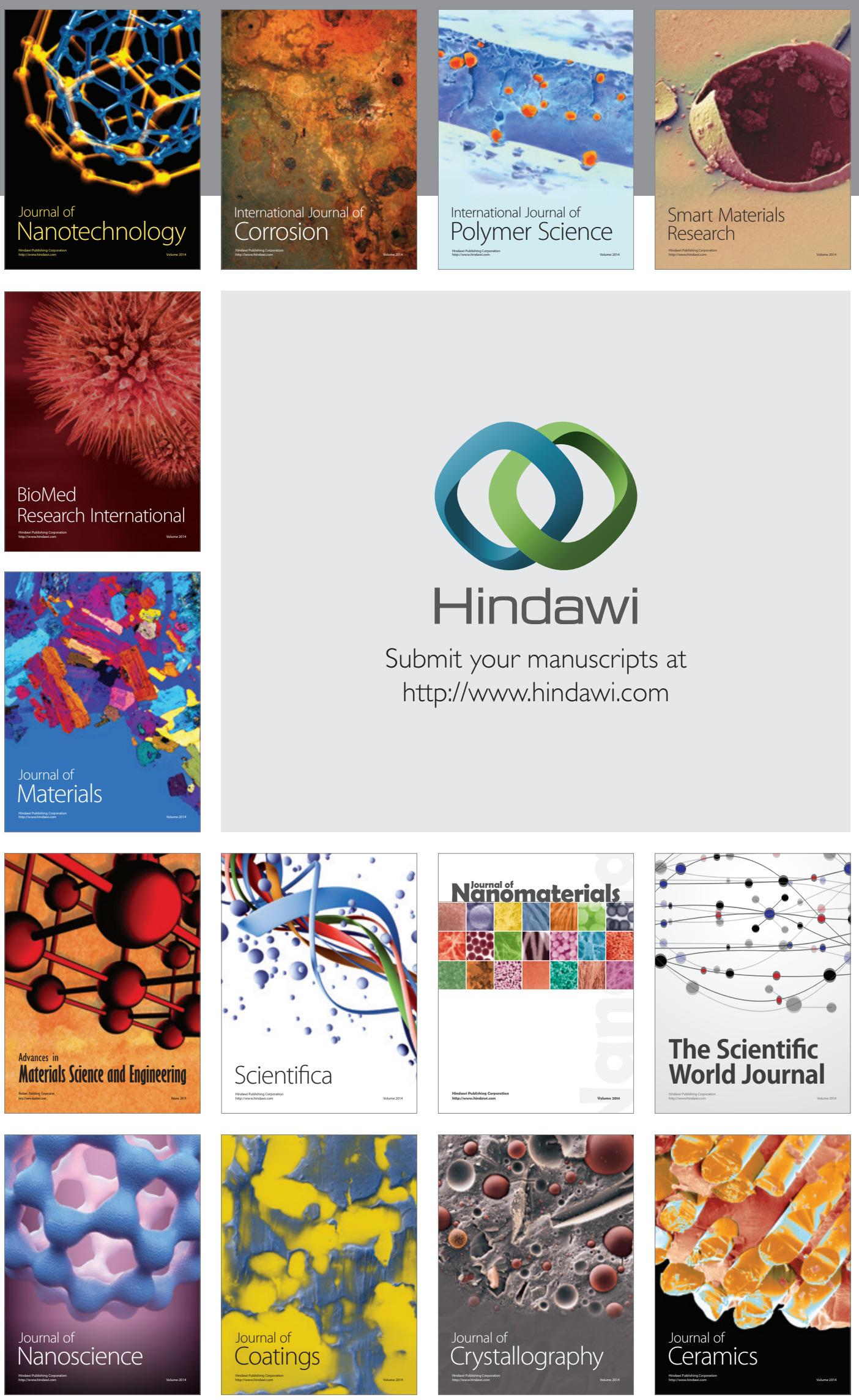

The Scientific World Journal

Submit your manuscripts at

http://www.hindawi.com

\section{World Journal}

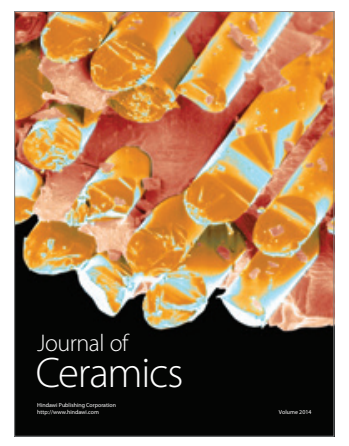

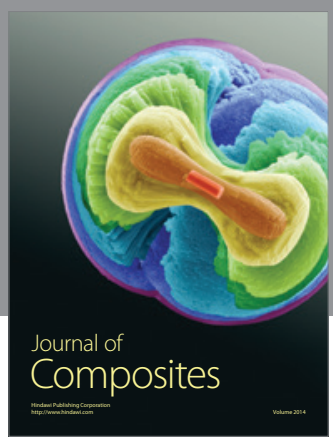
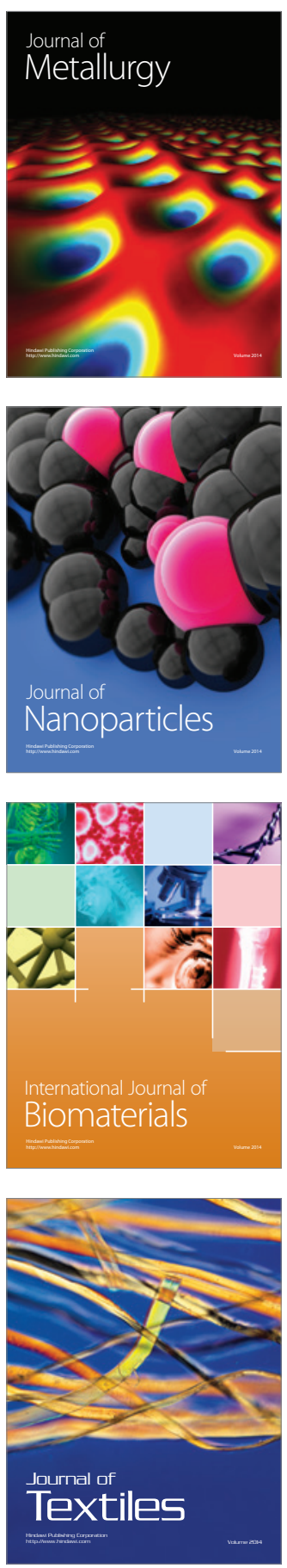